Javier Rueda Galvis* Mónica Rueda Galvis"

Universidad Cooperativa de Colombia Bogotá, Colombia

Recibido: 11 de marzo de 2016

Concepto de evaluación: 24 de febrero de 2017

Aprobado: 25 de mayo de 2017

Artículo de investigación

(C) 2017 Universidad Católica de Colombia.

Facultad de Ciencias

Económicas y Administrativas.

Todos los derechos reservados

* Profesor Investigador de la Universidad Cooperativa de Colombia, Sede Bucaramanga. Ph. D. en Ciencias Empresariales, Universidad Antonio de Nebrija en Madrid, España. Magíster en

Finanzas, Universidad Central. Magíster en Economía Aplicada, Universidad Antonio de Nebrija, Madrid, España. Administrador de Empresas y Especialista ISO 9000, Universidad Jorge Tadeo Lozano. email: javier.ruedag@ucc.edu.co

** Profesora Investigadora de la Universidad Cooperativa de Colombia. Magíster en Economía, Pontificia Universidad Javeriana. Economista, Universidad Santo Tomás. email: monica.ruedag@campusucc.edu.co
Finanz. polit. econ., ISSN: 2248-6046, Vol. 9, No. 2, julio-diciembre, 2017, pp. 319-344

http://dx.doi.org/10.14718/revfinanzpolitecon.2017.9.2.6

\section{Modelo econométrico de gestión exitosa para la empresa familiar colombiana"}

\section{RESUMEN}

Sobre la base de la gran importancia e impacto que representan actualmente las empresas familiares en el contexto económico global, resulta pertinente realizar esfuerzos enfocados a contribuir con su desarrollo, fortalecimiento, competitividad y sostenibilidad a través del tiempo, sobre todo si se ponen de presente sus debilidades de orden administrativo, a pesar de representar el 80\% de las organizaciones, el 70\% en generación de empleo y más del $50 \%$ del PIB en la mayoría de países alrededor del mundo. En este sentido, este artículo presenta un modelo econométrico de gestión basado en las variables más representativas asociadas al éxito empresarial en las organizaciones familiares, con la intención de ofrecer al lector un espacio de reflexión y análisis sobre su labor administrativa, a fin de implementar estrategias corporativas que promuevan la competitividad de sus organizaciones dentro del actual contexto de la globalización de los mercados.

Palabras clave: empresa familiar, estrategias competitivas, éxito empresarial, modelo econométrico de gestión.

JEL: C51, M16, M21

\section{An econometric model of successful management for Colombian family businesses}

\section{ABSTRACT}

Given the great importance and impact of family companies in the current global economic context, it is pertinent to make focused efforts to contribute to their development, strengthening, competitiveness, and sustainability over time, especially with regard of their administrative weaknesses, despite representing $80 \%$ of the organizations, $70 \%$ of employment generation, and more than $50 \%$ of GDP in most countries around the world. In this sense, this article presents an econometric management model based on the most representative variables associated with business success in family organizations,

\footnotetext{
* Artículo elaborado a partir de los resultados de la tesis doctoral "Modelo econométrico de gestión exitosa de las empresas familiares del sector confecciones en Colombia", evaluada sobresaliente Cum Laude (2012) en el Doctorado en Ciencias Empresariales de la Universidad Antonio de Nebrija, Madrid, España, estudios que fueron financiados por la Universidad de La Salle, sede Bogotá, Colombia.
} 
aiming to offer a space for analyzing and reflecting on their administrative work, in order to implement corporative strategies that promote the competitiveness of these organizations within the current context of globalized markets.

Keywords: family business, competitive strategies, business success, econometric management model.

\section{Modelo econométrico de gestão de sucesso para a empresa familiar colombiana}

\section{RESUMO}

Sobre a base da grande importância e impacto que representam atualmente as empresas familiares no contexto econômico global, resulta pertinente realizar esforços direcionados à contribuição do seu desenvolvimento, fortalecimento, competitividade e sustentabilidade através do tempo, principalmente se considerarmos as suas debilidades de ordem administrativa, apesar de representarem $80 \%$ das organizações, $70 \%$ em geração de emprego e mais de 50\% do PIB na maioria dos países. Nesse sentido, este artigo apresenta um modelo econométrico de gestão baseado nas variáveis mais representativas associadas ao sucesso empresarial nas organizações familiares, com a intenção de oferecer ao leitor um espaço de reflexão e análise sobre o seu trabalho administrativo, com a finalidade de implementar estratégias corporativas que promovam a competitividade das suas organizações dentro do atual contexto da globalização dos mercados.

Palavras-chave: empresa familiar, estratégias competitivas, modelo econométrico de gestão, sucesso empresarial. 


\section{INTRODUCCIÓN}

Con base en los postulados de Gaither y Frazier (1999), el propósito de toda organización debe ser estructurar ambientes de competitividad como parte de su misión empresarial, a fin de poder generar condiciones de desarrollo productivo superiores a las que alcanzan sus competidores en términos de desempeño en el mercado. En este sentido, Pfeffer (1998) afirma que el éxito empresarial surge como una consecuencia de la creación de valor en cada uno de los procesos productivos y gestión de la compañía. Esta dinámica implica la generación de elementos diferenciadores capaces de exponer ante sus clientes determinadas condiciones benéficas en función del consumo de sus productos o servicios.

Por esto, desde la perspectiva de Porter (1987), la idea del éxito empresarial se centraliza en la necesidad que tiene una organización de alcanzar condiciones diferenciales positivas frente a los competidores, aspecto que la hace ser más atractiva para los compradores y el mercado en general $y$, en esencia, le otorga el estatus de empresa exitosa. Consecuentemente, el nivel de competencia resulta ser el elemento que determina la condición de éxito o fracaso de una compañía, razón por la cual las organizaciones hoy en día se plantean la necesidad de encontrar aquellos elementos que constituyan verdaderos parámetros de crecimiento y sostenibilidad dentro de sus entornos de mercados.

Desde esta perspectiva, Berbis (2006) defiende que la condición de éxito de una empresa debe estar ligada al diseño permanente de nuevas estrategias que flexibilicen los actuales modelos de gestión y representen cambios significativos que constituyan una nueva ventaja competitiva $y$, al tiempo, permitan reaccionar rápida y asertivamente a las condiciones que imponen el entorno. Significa entonces que la dinámica sobre la cual una empresa es percibida como exitosa dependerá en gran medida de poder identificar qué elementos generan factores de productividad y competitividad. Este análisis implica la creación de valores agregados por parte de la compañía como condición fundamental, en función de poder lograr la capacidad de generar y retener clientes, a pesar de las abundantes y similares propuestas que el consumidor encuentra en el actual mercado globalizado (Kotler y Armstrong, 2003).

En otras palabras, alcanzar la condición exitosa en una organización demanda la búsqueda e identificación permanente de aquellos factores que hacen que las compañías adquieran valor, tarea en la que el ámbito académico debe y puede aportar elementos transcendentales para la definición de sistemas de gestión efectivos que potencialicen el papel que desempeñan inversionistas, directivos, empleados y comunidad en general en el fortalecimiento de las instituciones empresariales. Por estas razones, la presente investigación focaliza esfuerzos para lograr identificar e interpretar, mediante el desarrollo de un modelo econométrico propositivo, los factores o las dimensiones que las organizaciones deben visionar dentro de sus estructuras de gestión, especialmente en las empresas familiares, dada su gran importancia para el país en cuanto a volumen y los aportes que representan, con el propósito de impulsar su evolución y desarrollo en términos de capacidades competitivas.

\section{LA EMPRESA FAMILIAR Y LA IMPORTANCIA DE SER ORGANIZACIONES EXITOSAS}

Históricamente, la empresa familiar ha representado uno de los pilares más importantes en la construcción de Estados, crecimiento económico y calidad de vida para la población. Así los muestran múltiples cifras alrededor del mundo, que sostienen que el conjunto mayor de compañías pertenece a esta índole. Organizaciones familiares como Sony, Disney, Microsoft, Toyota, Televisa, Mercedes-Benz, Michelin, Benetton, Ford, Quilmes, Clarín, Arcor, Bacardí, Corte Inglés, José Cuervo, TV Azteca, BMW, General Electrics, entre miles más, dan buena medida de su impacto en cualquier sector de negocios en el ámbito global (Gallo y Amat, 2003; Arroyo y Barber, 2004; Serna y Suárez, 2005; Antognolli, 2008; Arrieta, 2009). 
Por esto, con base en la categoría que simboliza la empresa familiar en el ámbito internacional, Fundes Colombia (2008) destaca su importancia en el hecho de que representan cerca del $80 \%$ de las organizaciones del mundo, con una generación de empleos aproximada al $70 \%$ y más del $50 \%$ del producto interno bruto (PIB) de todo el planeta. Desde este contexto, se hace pertinente la realización de esfuerzos investigativos enfocados a contribuir con su desarrollo, competitividad y sostenibilidad a través del tiempo. Datos referenciados por Gallo (1996), Gersick et al. (1997), Neubauer y Lank (1999), Astrachan y Shanker (2003), Serna y Suárez (2005) y Trevinyo-Rodríguez (2010) señalan que las organizaciones de tipo familiar constituyen uno de los ejes principales del desarrollo económico de cualquier nación, al alcanzar promedios cercanos al $75 \%$ de su masa empresarial, que en países desarrollados incluso puede ser mayor, como sucede en Italia con 99\%, Estados Unidos con 96\%, Alemania con $93 \%$, Suiza con $88 \%$, Austria con $83 \%$ y Reino Unido con $76 \%$, etc. (gráfico 1 ).

En igual sentido, distintas cifras asociadas al valor de contribución que realizan las empresas familiares al PIB permiten afirmar que estas forjan valores promedios cercanos al $60 \%$ en cada país, con similares proporciones en temas referentes a la creación de empleo y el pago de impuestos estatales (Serna y Suárez, 2005). Otros estudios en la misma línea, como los de Gimeno (2004), con base en Donckels y Fröhlich (1991), Kang (2000) y Backes-Gellner (2001), dan cuenta de aportes adicionales de la empresa familiar en el mundo: señalan que el $30 \%$ de las compañías pertenecientes al grupo de Fortune 500 son de este tipo; aspectos similares se encuentran en Alemania, donde el $84 \%$ de las industrias son de este tipo, en tanto el $66 \%$ de las pymes del Reino Unido son compañías de orden familiar.

Complementariamente, Malfavón (2004) afirma que en Estados Unidos el número de empresas familiares oscila entre los 17 y 22 millones de negocios, cifra que demuestra su gran jerarquía y evolución, dado que para 1973 eran solo el $20 \%$ de las 500 mayores compañías, mientras que en 1983 lograron ser el $40 \%$ y para la década del 2000 lograron ser el $47 \%$, aportando anualmente el $45 \%$ del PIB norteamericano y $62 \%$ de la fuerza laboral. Frente a las empresas familiares europeas, Gallo (1995), Gallo y Amat (2003) y Efamiliar (2006) concluyen que estas logran ser el $70 \%$ del total de las organizaciones, con el $65 \%$ en generación del PIB, el $60 \%$ del total de las exportaciones y el $65 \%$ de los empleos. Ello tiene similares condiciones en el contexto latinoamericano, tal y como lo demuestran Trevinyo-Rodríguez (2010) y Boston Consulting Group (2011) en estudios que las identifican entre un $55 \%$ al $75 \%$, con concentraciones más altas en países como Colombia, Chile y Perú; aclaran que de incluir en las estadísticas los micronegocios informales familiares, el valor total lograría alcanzar montos superiores al $90 \%$.

En el caso particular de Colombia, el fenómeno de la empresa familiar alcanza cifras similares al promedio mundial, en la medida en que la Superintendencia de Sociedades ${ }^{1}$ (2006) concluyó que el $69,5 \%$ son organizaciones de esta índole ${ }^{2}$, las cuales soportan el $70 \%$ de los puestos de trabajo y aportan aproximadamente el $60 \%$ del PIB nacional. A partir de este informe, se logró ultimar que el $60 \%$ de las compañías familiares se encuentra aún en la etapa de primera generación, al estar en manos de su fundador, información que se soporta en el hecho de que el $73 \%$ fueron creadas entre 1970 y 1990 (entre 1971 y 1980 se constituyeron la mayoría de ellas: $79 \%$ ).

Ahora bien, teniendo en cuenta las afirmaciones de Lansberg, Perrow y Rogolsky (1988), Gallo (1995), Davis (2001), Belausteguigoitia (2003), Serna y Suárez (2005) y Ward (2006), entre otros, en las que postulan que el $50 \%$ de las empresas familiares logran sobrevivir en su camino hacia la segunda generación, el $12 \%$ a tercera generación y solo el $2 \%$ a cuarta generación, el panorama

1 La SuperSociedades es un organismo adscrito al Ministerio de Comercio, Industria y Turismo, que ejerce inspección, vigilancia y control de todas las actividades de las sociedades mercantiles en Colombia.

2 El estudio de SuperSociedades (2006) es el último elaborado hasta la fecha; está soportado en la información extraída de los estados financieros de 19.109 empresas familiares colombianas, reportados al cierre contable de 31 de diciembre de 2005. 
Porcentajes de la empresa familiar en el mundo

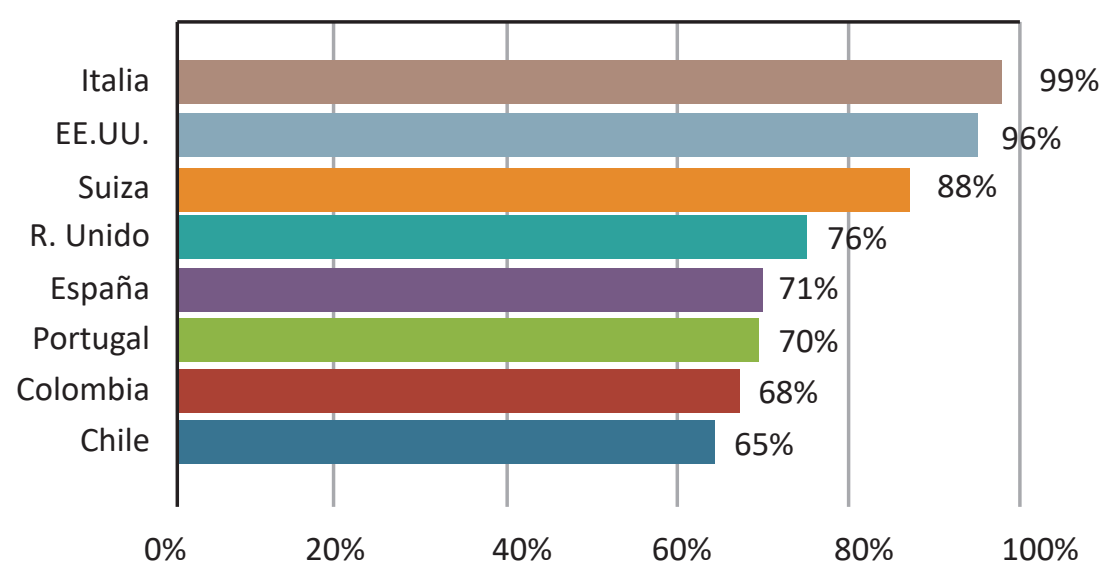

Fuente: Serna y Suárez (2005).

para estas organizaciones en Colombia resulta ser preocupante actualmente, en la medida en que es posible predecir que antes del 2020 se debe presentar el primer cambio generacional en más de 100.000 compañías familiares, situación que las ubica en un alto riesgo en términos de supervivencia y competitividad. Sumado a lo anterior, como lo señalan en sus investigaciones la Cámara de Comercio de Bogotá (2006) y SuperSociedades (2006), no es alentador que la mayoría de las empresas familiares colombianas sean micro, pequeña o mediana (gráfico 2), dado que la evidencia señala marcadas falencias en los modelos de gestión de las mipymes en cuanto a recursos financieros, sistemas de producción y niveles de profesionalización, aspectos que han generado tasas de mortandad del $50 \%$ en los primeros diez años de funcionamiento.

Como ejemplo de lo anterior, el nivel de rentabilidad de la empresa familiar colombiana es menor que el de sus pares no familiares, en la medida en que con el $40 \%$ de sus ingresos generan solo un $21 \%$ en utilidades netas, mientras que las no familiares, con el $60 \%$, alcanzan utilidades cercanas al $79 \%$. Este aspecto está asociado a que estas últimas realizan mayores inversiones en tecnología, infraestructura y profesionalización, lo que conduce a procesos más productivos en menores tiempos y costos. También se observa que las organizaciones no familiares en Colombia resultan ser más competitivas en el mercado extranjero: logran exportar un $17,3 \%$ del valor de sus ingresos operacionales frente al bajo $8,3 \%$ de las familiares, lo que a su vez las hace menos rentables, al obtener un promedio anual del $5,3 \%$ frente al $13,6 \%$ de las no familiares (SuperSociedades, 2006).

En consecuencia, la situación de la empresa familiar nacional se puede resumir como preocupante, dadas las manifiestas debilidades organizacionales que posee, aspectos que no le permite alcanzar adecuados niveles de desarrollo productivo tanto en el contexto local como internacional. Como se puede observar a continuación, las principales falencias de la empresa familiar colombiana se centralizan en la ausencia de un modelo de gestión, lo que, sumado a las problemáticas propias de este tipo de organizaciones, entendidas como aquellos conflictos generados por la interrelación entre propiedad, familia y empresa señalados en el esquema de los tres círculos propuesto por Davis y Tagiuri (1996), hace que la visión de futuro para gran parte de estas compañías resulte innegablemente compleja, dado el alto nivel de vulnerabilidad y riesgo que enfrentan en el actual entorno económico de competitividad 
Tamaño de la empresa familiar colombiana

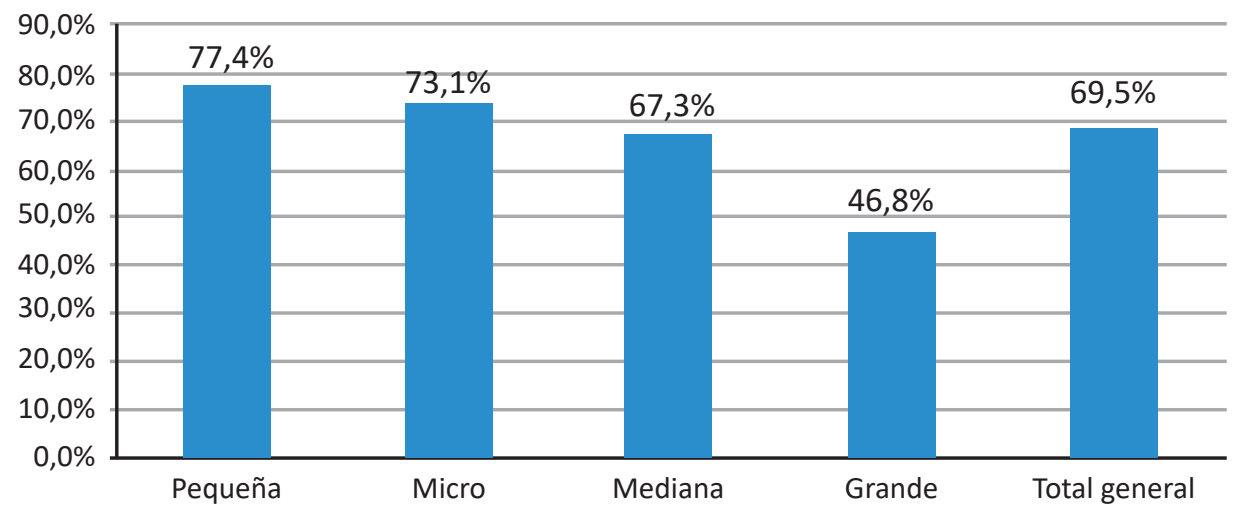

Fuente: SuperSociedades (2006).

globalizada, situación que se representa en los siguientes hechos con base en Serna y Suárez (2005), SuperSociedades (2006), Gómez-Betancourt (2006) y Romero (2006):

- El $30 \%$ de las empresas familiares colombianas ha sobrevivido a su primer cambio generacional, mientras que solo el $8 \%$ llega a la tercera generación.

- En Colombia, solo el $13 \%$ de las empresas familiares afirma poseer un protocolo familiar.

- El $89 \%$ de las empresas familiares nacionales no posee planes de sucesión ni cambio generacional.

- $\quad$ El $79 \%$ de estas no cuenta con procedimientos para el proceso de selección de un nuevo sucesor.

- A la fecha, en Colombia el $60 \%$ de las empresas familiares son dirigidas por su fundador.

- Solo el 8,5\% de las empresas familiares cuenta con el diseño de protocolos de buen gobierno.

- Tan solo el $14 \%$ de las empresas familiares tiene establecido un consejo de familia.

- En la empresa familiar colombiana, el $70 \%$ de los empleados que poseen vínculos familiares nunca presentó procesos de selección de personal ni cumple con el perfil laboral del cargo.

- El $91 \%$ de las empresas familiares no reconoce el pago de honorarios a los miembros familiares que integran la junta directiva.

- Solo el 36\% de las empresas familiares suele vincular miembros externos como integrantes de la junta directiva de la organización.

- Solo el $25 \%$ de las juntas directivas de los negocios familiares se reúne una vez cada mes, el $18 \%$ lo hace una vez cada seis meses y el $21 \%$ se reúne una vez cada año.

- Más del $50 \%$ de las empresas familiares afirma nunca haber contratado servicios de asesoría o consultoría profesional.

- Cerca del 73\% de estas empresas de familia en Colombia fueron creadas en la década de los setenta, lo que significa que de 2000 al 2020, aproximadamente 100.000 compañías deben realizar su primer cambio generacional.

En concordancia con el anterior análisis, es posible concluir que de no promover a tiempo adecuados procesos de gestión en la empresa familiar colombiana, se puede desencadenar para el país un fuerte impacto de orden económico y social, 
por cuanto este tipo de empresas son las instituciones que más aportan a la generación de riqueza y puestos de trabajo. Por lo tanto, a continuación se presenta el resultado de la investigación realizada para el desarrollo de un modelo econométrico de gestión, el cual fue diseñado a partir del análisis de los datos obtenidos en organizaciones familiares que han demostrado comportamientos exitosos en los últimos años en Colombia. Todo ello tiene como propósito ofrecer un elemento guía para el debate, la reflexión y una posible formulación de estrategias de dirección que mejoren las condiciones actuales de productividad y sostenibilidad que precisan estas organizaciones en el actual contexto competitivo mundial.

\section{MODELO ECONOMÉTRICO DE GESTIÓN PARA EL ÉXITO DE LA EMPRESA FAMILIAR}

\section{Formulación del modelo y metodología investigativa}

El modelo econométrico propositivo de una gestión exitosa para la empresa familiar colombiana se estructuró a partir de la formulación de siete dimensiones o variables internas que, desde el contexto teórico y práctico, argumentan de la mejor manera el adecuado desempeño administrativo y la estructuración de escenarios que permitan alcanzar la condición de empresa exitosa en cualquier tipo de organización familiar en el ámbito mundial. En este sentido, la ecuación incorpora variables fundamentales de una buena gestión y proceder corporativo, a saber: calidad total, innovación, talento humano, servicio al cliente, planeación estratégica, comportamiento organizacional y empresa familiar. Esta última es una variable propia del estudio, dado el interés de verificar el nivel de impacto como condición que contribuye o no al logro del éxito empresarial (ecuación [1]):

Éxito empresa familiar (EEF) $=(C E F)+($ IEF $)+(T H E F)$

$+(S C E F)+(P E I E F)+(C O E F)+(E F)+k$
La formulación del problema de investigación se planteó sobre el análisis de poder explicar qué variables generan un aporte significativo al fenómeno particular del éxito empresarial en organizaciones de tipo familiar, aspecto que conllevó proponer la siguiente pregunta de investigación: ¿cuáles son los factores que en el contexto interno deben desarroIlan las organizaciones familiares para lograr el éxito empresarial en Colombia? Consecuentemente, para validar el modelo, se formularon hipótesis que se analizaron inicialmente mediante la realización de entrevistas formales a nueve expertos académicos a partir del método Delphi, lo que, sumado en segunda instancia a la información aportada por medio de la aplicación de encuestas formales a diecinueve grandes empresas familiares colombianas del sector confecciones (anexo 1 y 2), permitió obtener datos estadísticos para el análisis y la identificación de las relaciones que existen entre las variables asociadas a los factores internos que posicionan a una compañía como exitosa en Colombia (Tamayo, 1994; Van-Dalen y Meyer, 2004).

Es oportuno señalar que los argumentos que motivaron a concentrar la investigación en empresas familiares colombianas del sector confecciones se basan en la gran importancia que este representa para el país, dado que produce el $7,4 \%$ del PIB nacional, con más de $\$ 4$ billones de pesos anuales (SuperSociedades, 2008; Rendón, 2014), empleos sostenidos del $21 \%$ del total manufacturero nacional, con 130.000 empleos directos y 1.000 .000 indirectos, 107 trabajadores promedio por empresa (79 media nacional) y el 5\% de las exportaciones, lo cual ubica a Colombia en el lugar 45 de países comercializadores de confecciones, con el $0,32 \%$ del consumo mundial (Escorcia y Duque, 2005; Fracica et al., 2008).

\section{Análisis estadístico e interpretación de resultados}

Con base en la información obtenida a partir del panel de expertos realizado con el método Delphi, se pudo establecer como aspectos más relevantes 
de la dimensión interna, que se consideran generan una mayor contribución al éxito empresarial, la planeación estratégica, con un nivel de respuesta del $67 \%$, seguida por la variable de servicio al cliente, con un $45 \%$ (gráfico 3 ). La razón dada de por qué implementar la planeación estratégica es la dimensión más significativa para el logro del éxito se soporta en que es una herramienta administrativa que ofrece a directivos un campo de acción para la toma de decisiones efectivas en función de la misión y la visión de la empresa, a partir del análisis de la situación actual y la futura que desea alcanzar la compañía.

Frente al interrogante sobre cuál es la dimensión interna que consideran menos aportes representa en función de lograr el éxito empresarial, se obtuvo con un $56 \%$ de las respuestas el factor "ser una empresa familiar", sin identificarse claramente una segunda variable en este aspecto (gráfico 4). En este caso, los expertos identifican este factor como negativo, en la medida en que consideran que ser actualmente una empresa familiar no representa grandes ventajas competitivas, dados los continuos conflictos de intereses entre directivos $y$ familia, que desencadenan un desorden organizacional propio de este tipo de compañías.
En cuanto a la información obtenida a través de las encuestas realizadas a los directivos de las grandes empresas familiares del sector confecciones, se identificó, mediante análisis cuantitativo, un logro de los parámetros de las dimensiones de éxito en sus organizaciones del $87 \%$ en promedio. Este hecho señala que son compañías que desarrollan con seriedad y profesionalismo la gestión en cada uno de sus procesos productivos y administrativos. Igualmente, es importante resaltar que el 52,63\% de las empresas alcanzaron valores superiores al $90 \%$ en cuanto al logro de las dimensiones, aspecto que se refleja en el alto posicionamiento de estas empresas en términos de marcas y ventas (gráfico 5).

Al identificar las dimensiones que mayor aporte generan al éxito empresarial según los directivos, se destacó notablemente, en primer lugar, la variable de servicio al cliente, con un valor del $95,58 \%$ (gráfico 6), cifra soportada en que esta gestión permite generar mayores grados de diferenciación con el cliente y el sector. Este elemento resulta de gran validez, dado que el mercado de comercialización de prendas de vestir se formula como objetivo la fidelización, razón por la cual las organizaciones realizan grandes esfuerzos por garantizar la plena satisfacción del cliente, mediante

Dimensiones de mayor contribución al éxito según expertos

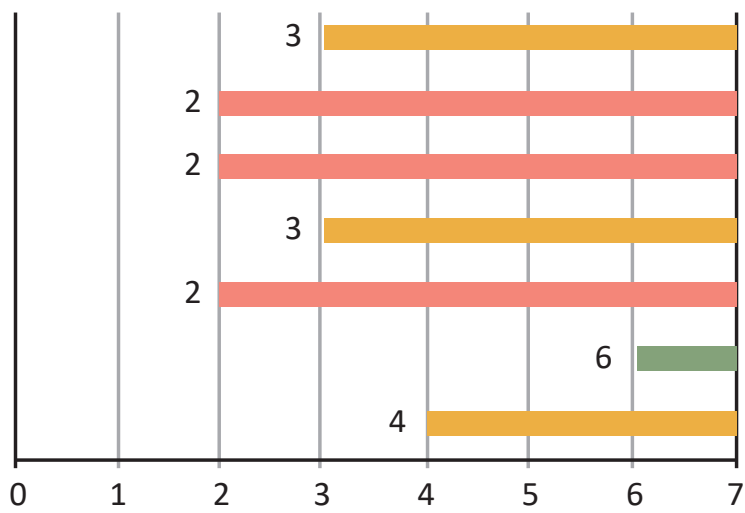

La condición de ser una empresa familiar La cultura empresarial y responsabilidad social El nivel profesional del recurso humano La innovación de sus productos y servicios La calidad de sus procesos/productos La planeación estratégica El servicio al cliente

Fuente: elaboración de los autores. 
Dimensiones con menor contribución al éxito según expertos

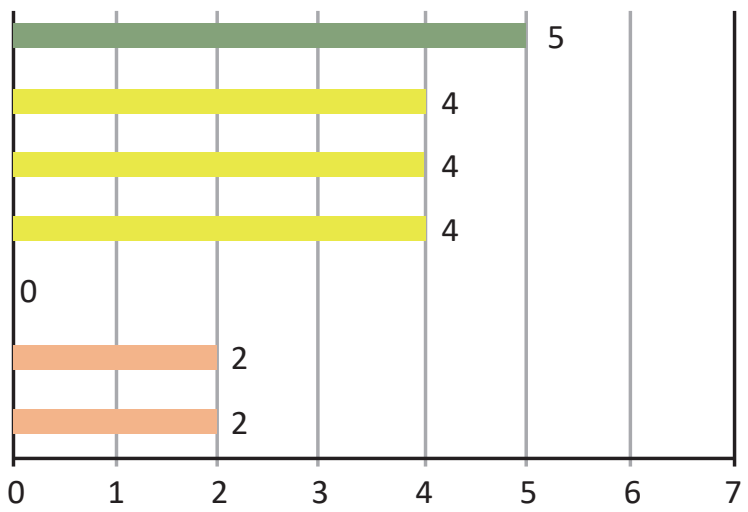

La condición de ser una empresa familiar La cultura empresarial y responsabilidad social

El nivel profesional del recurso humano La innovación de sus productos y servicios La calidad de sus procesos/productos La planeación estratégica

El servicio al cliente

Fuente: elaboración de los autores.

\section{Gráfico 5.}

Porcentajes de logro del éxito en las empresas participantes

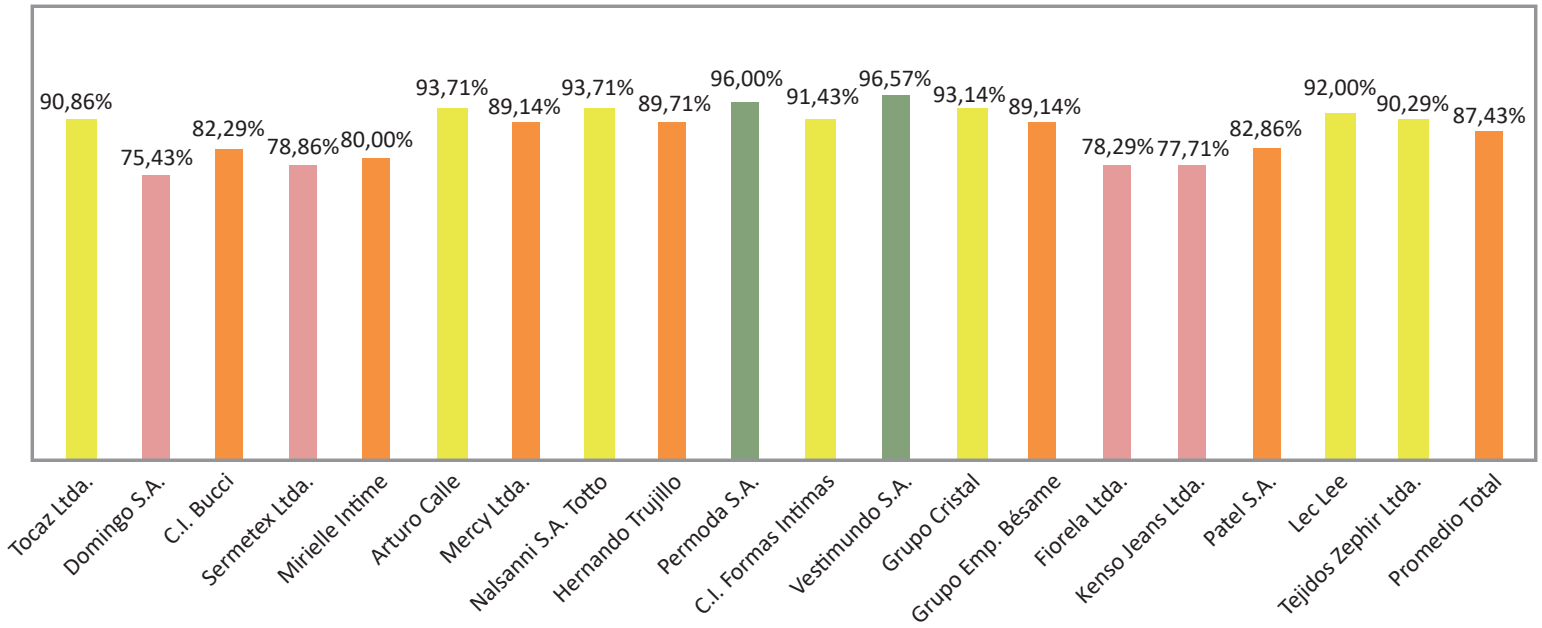

Fuente: elaboración de los autores.

estrategias de frente a la marca y los productos en términos de atención prestada en puntos de venta y servicios de soporte.

Los directivos de empresas familiares reconocen la dimensión de talento humano, con un $90,74 \%$, como la segunda variable más influyente para lograr el éxito, situación que se explica en que el personal (operarios, administrativos y comerciales), a través de su labor, garantizan en gran medida la calidad de los procesos, productos, servicios y desarrollo de nuevas ideas. En tercer lugar, surge la dimensión de innovación, con $87,58 \%$, como factor de éxito, pues se reconoce que por, tratarse de prendas de vestir, la variedad en el diseño de producto y la creación de nuevos conceptos son elementos vitales dentro de la competitividad que demanda el sector tanto en el ámbito local como internacional. 


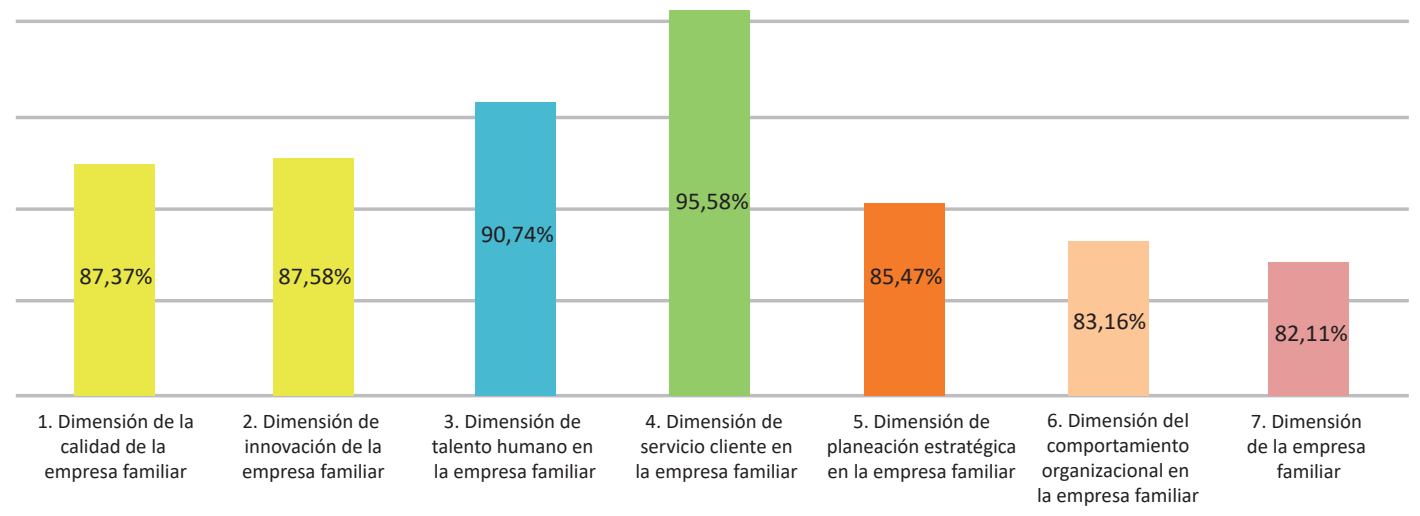

Fuente: elaboración de los autores.

En el análisis comparativo entre las respuestas dadas por empresarios en oposición a expertos, se identifica una diferencia de percepciones, en la medida en que para los segundos la planeación estratégica es considerada como la de mayor grado de contribución en el éxito corporativo; variable que para directivos solo se ubica en el quinto lugar de preferencia, con un $85,47 \%$ (tabla 1 ). Resulta interesante observar que las variables de servicio al cliente y calidad representan niveles altos en ambas percepciones, al igual que las dimensiones de comportamiento organizacional y empresa familiar-familiness, como las de menor relevancia en el éxito empresarial, situación argumentada en que por ser grandes compañías, los niveles de profesionalización son altos y se manejan protocolos en la toma de decisión, logrando así la adecuada separación entre los ambiente de familia, propiedad y empresa.

Complementario a este análisis descriptivo, se realizó el cálculo del índice de la correlación de Pearson (tabla 2), el cual reflejó el grado en que las variables están relacionadas entre sí, situación que expresa los niveles de dependencia o independencia entre ellas $(-1<r<1)$, entendiendo que entre más cercano sea a 1 , es posible argumentar una correlación positiva que revelaría dependencias directas entre variables, es decir, que si una de ellas

Tabla 1 .

Valoración dimensiones más importantes para el éxito

\begin{tabular}{|c|c|c|}
\hline N. ${ }^{\circ}$ & Importancia según empresarios & Importancia según expertos \\
\hline 1 & Servicio al cliente: $95,58 \%$ & Planeación estratégica \\
\hline 2 & Talento humano: $90,74 \%$ & Servicio al cliente \\
\hline 3 & Innovación: $87,58 \%$ & Calidad \\
\hline 4 & Calidad: $87,37 \%$ & Talento humano \\
\hline 5 & Planeación estratégica: $85,47 \%$ & Innovación \\
\hline 6 & Comportamiento organizacional: $83,16 \%$ & Comportamiento organizacional. \\
\hline 7 & Familiness: $82,11 \%$ & Familiness \\
\hline
\end{tabular}

Fuente: elaboración de los autores. 
cambia sus valores, la otra lo hace en similares o iguales proporciones. Si el número del índice de correlación tiende a ser -1 , se interpreta una relación negativa o inversa, mientras que si el valor tiende a cero $(0)$, no existe relación entre variables (Meza, 2007).

Se demuestra con lo anterior que existen cinco niveles de correlación altamente significativos, dentro de los que se destacan especialmente los valores alcanzados entre las dimensiones de la calidad con las de comportamiento organizacional $(r=0,78)$ y talento humano $(r=0,71)$ con familiness $(r=0,71)$. La fuerte correlación de 0,78 existente entre la dimensión de la calidad y comportamiento organizacional permite entender que, al gestionar el aumento de una unidad de valor en la dimensión de la calidad, existirá una variación proporcional positiva del 0,78 en la dimensión de comportamiento organizacional, y viceversa.

Otro de los resultados del estudio es la correlación importante entre las dimensiones de familiness, talento humano y calidad, de un 0,71 , con una fuerte interacción que implica dependencias positivas. Finalmente, la dimensión de familiness alcanza una correlación de 0,68 frente al comportamiento organizacional y de 0,65 con planeación estratégica, situación que representa dependencias positivas entre estas variables.

\section{Diseño del modelo econométrico propositivo}

Tras establecer cuáles son, según los expertos y empresarios, las variables que explican el éxito de sus organizaciones familiares, el objetivo subsecuente en esta investigación fue diseñar un modelo econométrico propositivo que identificara qué factores permiten incrementar la condición actual de éxito empresarial. Como lo expresan Meza (2007), Guerrero (2008) y Pérez y Fernández (2009), los principios de la literatura econométrica instituyen

Tabla 2.

Correlación entre resultados de las dimensiones del éxito

\begin{tabular}{|c|c|c|c|c|c|c|c|}
\hline Análisis de correlación & $\begin{array}{c}1 . \\
\text { Dimensión } \\
\text { de la } \\
\text { calidad } \\
\text { de la } \\
\text { empresa } \\
\text { familiar }\end{array}$ & $\begin{array}{c}2 . \\
\text { Dimensión } \\
\text { de } \\
\text { innovación } \\
\text { de la } \\
\text { empresa } \\
\text { familiar }\end{array}$ & $\begin{array}{c}3 . \\
\text { Dimensión } \\
\text { de talento } \\
\text { humano } \\
\text { de la } \\
\text { empresa } \\
\text { familiar }\end{array}$ & $\begin{array}{c}4 . \\
\text { Dimensión } \\
\text { de servicio } \\
\text { al cliente } \\
\text { de la } \\
\text { empresa } \\
\text { familiar }\end{array}$ & $\begin{array}{c}5 . \\
\text { Dimensión } \\
\text { de } \\
\text { planeación } \\
\text { estratégica } \\
\text { de la } \\
\text { empresa } \\
\text { familiar }\end{array}$ & $\begin{array}{l}\text { 6. Dimensión de } \\
\text { comportamiento } \\
\text { organizacional } \\
\text { de la empresa } \\
\text { familiar }\end{array}$ & $\begin{array}{c}7 . \\
\text { Dimensión } \\
\text { familiness } \\
\text { de la } \\
\text { empresa } \\
\text { familiar }\end{array}$ \\
\hline $\begin{array}{l}\text { 1. Dimensión de la calidad de la } \\
\text { empresa familiar }\end{array}$ & 1,00 & & & & & & \\
\hline $\begin{array}{l}\text { 2. Dimensión de innovación de } \\
\text { la empresa familiar }\end{array}$ & 0,14 & 1,00 & & & & & \\
\hline $\begin{array}{l}\text { 3. Dimensión de talento } \\
\text { humano de la empresa familiar }\end{array}$ & 0,71 & 0,30 & 1,00 & & & & \\
\hline $\begin{array}{l}\text { 4. Dimensión del servicio al } \\
\text { cliente de la empresa familiar }\end{array}$ & 0,21 & 0,50 & 0,34 & 1,00 & & & \\
\hline $\begin{array}{l}\text { 5. Dimensión de planeación } \\
\text { estratégica de la empresa } \\
\text { familiar }\end{array}$ & 0,55 & 0,35 & 0,50 & 0,26 & 1,00 & & \\
\hline $\begin{array}{c}\text { 6. Dimensión de } \\
\text { comportamiento organizacional } \\
\text { de la empresa familiar }\end{array}$ & 0,78 & 0,13 & 0,60 & 0,21 & 0,60 & 1,00 & \\
\hline $\begin{array}{l}\text { 7. Dimensión familiness de la } \\
\text { empresa familiar }\end{array}$ & 0,71 & 0,02 & 0,55 & 0,16 & 0,65 & 0,68 & 1,00 \\
\hline
\end{tabular}

Fuente: elaboración de los autores. 
que, si solamente existen variables independientes en el fenómeno de estudio, el diseño del modelo demanda la aplicación de la técnica de análisis factorial ${ }^{3}$, la cual permite realizar análisis lógicos y la reducción de datos para explicar los niveles de variabilidad en función del número de elementos no observables. Ello permitirá modelar a partir de combinaciones lineales de factores sobre la base de identificar cuáles de ellos representan interrelaciones positivas o importantes.

Por tal razón, el modelo econométrico se construyó aplicando el método de análisis factorial, situación justificada en que el fenómeno del éxito empresarial no es una variable independiente observable sino dependiente, que responde, en consecuencia, al comportamiento de otros factores o dimensiones, tales como la calidad, la innovación, el servicio al cliente, etc. De acuerdo con BatistaFogueta, Coendersb y Alonso (2004), el análisis factorial permite reducir los datos iniciales hasta una cantidad adecuada de factores representativos del fenómeno, mediante la técnica del análisis factorial de correlaciones, la cual en este caso fue útil para encontrar el grupo homogéneo de variables que tienen asociación lineal como elementos representativos del éxito empresarial. De este modo, es posible identificar la información verdaderamente relevante de los 670 valores obtenidos en las encuestas aplicadas a las organizaciones familiares participantes en la investigación.

Aplicando cada uno de los procedimientos descritos anteriormente, se calculó inicialmente el componente óptimo de los factores, donde se observan los eigenvalues o valores propios de la matriz varianza y covarianza; se entiende que estos expresan el grado de dispersión de las variables con

3 La técnica de análisis factorial posee la gran ventaja de simplificar la modelización de comportamientos del fenómeno, en la medida en que elimina variables que tienden a ser redundantes o reiterativas, expresando cuáles poseen altos niveles de correlación, lo cual convierte un conjunto amplio de variables en uno mucho más limitado en factores "estructurales". Los beneficios de aplicar el análisis factorial se centralizan en modelar de forma directa información de variables que representan factores "no observables", a tiempo que disminuye ampliamente el conjunto de datos y logra esclarecer las diferentes relaciones existentes con pérdidas muy bajas de información procesada. respecto a la media, es decir, la varianza total que explica a cada factor. El análisis factorial establece, en este sentido, que deben seleccionarse aquellos factores cuyos eigenvalues sean mayores a 1,0, pues solo estos explican mayormente el comportamiento de la varianza y el grado de independencia de las variables estudiadas, con la condición importante de que los factores seleccionados deben estar dentro de un intervalo de confianza igual o superior a $90 \%$, demostrando estar dentro de los parámetros establecidos en la zona de aceptación por la función chi (chi cuadrado ${ }^{4}$ ).

En este sentido, la tabla 4 demuestra que existen siete eigenvalues con un valor de $\mathrm{chi}^{2}$ menor a 0,05 , hecho que manifiesta estadísticamente que las variables analizadas son completamente independientes entre sí. Igualmente, se evidencia que el factor 1 (calidad) es el único elemento con eigenvalues superior a 1,0, al alcanzar un valor de 3,35 , que al mismo tiempo representa el $86,39 \%$ de la varianza de los datos examinados originalmente.

Como el factor 1 (calidad) representa un $86,39 \%$, significa que no logra alcanzar el valor mínimo establecido de confianza del 90\%, situación que hace necesario efectuar un nuevo cálculo mediante análisis factorial que reduzca el número de variables, a fin de que se puedan alcanzar niveles de confianza mayores a 90\% para dar explicación al fenómeno. Realizado este procedimiento, se generó la tabla 5, donde se puede prestar atención a la reducción notable de factores, alcanzando así el nivel de confianza solicitado, que para el caso resultan ser las dimensiones de calidad, innovación y planeación estratégica como las más representativas para explicar el éxito empresarial en las organizaciones familiares.

Hasta este momento se concluye que los factores determinantes del éxito en las empresas familiares son la dimensión de la calidad como factor 1 , con un $85,83 \%$; la dimensión de la innovación como factor 2 , con un $63,73 \%$, y

$4 \quad$ En los análisis de distribución se utiliza el concepto de $C h i^{2}$ como un elemento de inferencia estadística que se esgrime como prueba de independencia de las variables y el cálculo de estimación de la varianza. 
Tabla 4.

Factores principales y varianza

\begin{tabular}{|c|c|c|c|c|}
\hline Correlación del análisis factorial & \multicolumn{2}{|c|}{ Numero de observaciones $=19$} & & \\
\hline Método: factores principales & \multicolumn{2}{|c|}{ Factores retenidos $=3$} & & \\
\hline Rotación: (sin girar) & \multicolumn{3}{|c|}{ Numero de parámetros $=18$} & \\
\hline Factores /dimensiones & Valores propios & Diferencias & Proporción & Acumulado \\
\hline Factor 1: calidad & 3,35842 & 2,54259 & 0,8639 & 0,8639 \\
\hline Factor 2: innovación & 0,81583 & 0,64397 & 0,2098 & 1,0737 \\
\hline Factor 3: talento humano & 0,17186 & 0,20022 & 0,0442 & 1,1179 \\
\hline Factor 4: servicio al cliente & $-0,02836$ & 0,03949 & $-0,0073$ & 1,1106 \\
\hline Factor 5: planeación estratégica & $-0,06785$ & 0,05580 & $-0,0175$ & 1,0932 \\
\hline Factor 6: comportamiento organizacional & $-0,12365$ & 0,11488 & $-0,0318$ & 1,0614 \\
\hline Factor 7: familiness & $-0,23853$ & 0,00000 & $-0,0614$ & 1,0000 \\
\hline \multicolumn{5}{|c|}{ LR test: independentes vs. saturados: $C h i^{2}(21)=59,60$ Prob $>C h i^{2}=0,0000$} \\
\hline
\end{tabular}

Fuente: elaboración de los autores.

Tabla 5.

Factores principales y varianza

\begin{tabular}{|c|c|c|c|c|}
\hline Variables & Factor 1 & Factor 2 & Factor 3 & Singularidad \\
\hline Calidad & 0,8583 & $-0,1851$ & $-0,1764$ & 0,1979 \\
\hline Innovación & 0,3056 & 0,6373 & 0,0337 & 0,4994 \\
\hline Talento humano & 0,7553 & 0,1000 & $-0,1927$ & 0,3824 \\
\hline Servicio al cliente & 0,3536 & 0,5042 & $-0,0456$ & 0,6186 \\
\hline Planeación estratégica & 0,7380 & 0,0878 & 0,2786 & 0,3701 \\
\hline Comportamiento organizacional & 0,8185 & $-0,1717$ & $-0,0244$ & 0,2999 \\
\hline Familiness & 0,7863 & $-0,2721$ & 0,1490 & 0,2855 \\
\hline
\end{tabular}

Fuente: elaboración de los autores.

la dimensión de la planeación estratégica como factor 3 , con un $27,86 \%$. Es oportuno resaltar que el éxito empresarial es una variable latente o no observable, es decir, que representa como tal una variable dependiente de las demás y que explica su comportamiento a partir del desempeño de las tres dimensiones descritas. En esta fase, el análisis factorial establece que es obligatorio realizar una corrección de la matriz varianza y covarianza, para poder corregir los posibles errores de estimación en los datos obtenidos, lo cual se efectúa mediante la matriz de rotación de factores, haciendo que el modelo econométrico sea más confiable, dados los ajustes en términos del grado de dispersión de cada factor (tabla 6).
Tabla 6.

Rotación de factores variación máxima corregida

\begin{tabular}{|c|r|r|r|}
\hline Variables* & \multicolumn{1}{|c|}{ Factor 1 } & Factor 2 & Factor 3 \\
\hline Calidad & 0,43555 & $-0,07583$ & $-0,43086$ \\
\hline Innovación & $-0,06179$ & 0,43216 & 0,05313 \\
\hline Talento humano & 0,12995 & 0,22556 & $-0,23430$ \\
\hline Servicio al cliente & $-0,02934$ & 0,31418 & $-0,03979$ \\
\hline $\begin{array}{c}\text { Planeación } \\
\text { estratégica }\end{array}$ & 0,05075 & 0,17864 & 0,46226 \\
\hline $\begin{array}{c}\text { Comportamiento } \\
\text { organizacional }\end{array}$ & 0,23319 & $-0,05674$ & 0,04509 \\
\hline Familiness & 0,23319 & $-0,21890$ & 0,37962 \\
\hline
\end{tabular}

*El coeficiente de puntuación se calculó bajo el método de regresión, basado en variación de factores girados.

Fuente: elaboración de los autores. 
Se interpreta entonces que las dimensiones de calidad, innovación y planeación estratégica explican en un $90 \%$ el fenómeno de generación del éxito en las empresas familiares. Esto no significa que las demás dimensiones o factores no contribuyan en este propósito, sino que lo hacen en una escala de valores poco significativa en comparación con las tres antes mencionadas. En definitiva, a partir de los datos ajustados, los valores por efecto de la corrección de la varianza con mayor nivel de importancia sobre las variables determinantes del éxito en las empresas familiares son:

- Factor 1: dimensión de la calidad, con un 43,55\%.

- Factor 2: dimensión de la innovación, con un $43,21 \%$.

- Factor 3: dimensión de la planeación estratégica, con $46,22 \%$.

Por lo tanto, es de vital importancia comprender que si las organizaciones familiares, adicionalmente a los esfuerzos realizados en servicio al cliente y talento humano, implementan las variables del modelo econométrico propositivo resultante, estas pueden lograr mejorar su condición de éxito empresarial (con un nivel de confianza del $90 \%)$ si estructuran acciones que promuevan las dimensiones descritos en la ecuación [2].

$E E F=44 \%$ calidad $+43 \%$ innovación $+46 \%$ planeación estratégica $+k$

En otras palabras, este modelo econométrico propositivo debe interpretarse como la representación matemática de tres factores independientes (no una sumatoria de $100 \%$ ), que en su orden permiten pronosticar un incremento porcentual del éxito actual de las empresas familiares en los valores establecidos. Significa entonces que las empresas familiares, para incrementar su condición de éxito, deben generar acciones estratégicas en todas las dimensiones propuestas, pero gestionando mayores esfuerzos en los factores de calidad, innovación y planeación estratégica, situación que reflejará en cada uno de ellos un incremento porcentual de su condición actual exitosa en valores superiores al $40 \%$.

\section{Análisis de cada dimensión que contribuyen al éxito de la empresa familiar}

\section{Análisis de la dimensión de la calidad}

Tras definir las dimensiones que se explican a través del modelo econométrico el éxito empresarial, resulta necesario identificar qué variables propias de cada uno de los tres factores son las que mayor nivel de aporte o impacto positivo ejercen para la obtención del éxito. Significa que, realizando los procedimientos descritos para cada una de las tres dimensiones, es posible establecer qué variables son independientes al obtener un $\mathrm{Chi}^{2}$ menor a 0,05 (tabla 7). Se encontró el factor 1: control total de calidad, como el más representativo, al poseer un eigenvalues del 1,28 (mayor a 1,0), aunque alcanzaba un $62,76 \%$ de nivel de confianza (no superior al $90 \%)$, por lo cual se hizo necesario desarrollar el procedimiento de reducción de factores.

Tras disminuir la cantidad de factores a tres para lograr los niveles de confianza del $90 \%$, se identificó que de las cinco variables asociadas con la dimensión de la calidad, las más representativas para el modelo fueron en su orden: factor 1 , certificación en normas ISO 9000, con 77,40\%; factor 2 , calidad superior a competidores, con $65,90 \%$, y factor 3 , certificación en normas ISO 14000, con $38,82 \%$ (tabla 8).

En esta etapa, el modelo de análisis factorial necesita efectuar ajustes correctivos a la varianza, por lo que se vuelva a utilizar este procedimiento para descubrir el peso real de cada factor. Realizado este ajuste de rotación, se observa en la tabla 9 que surgen tres variables como las más representativas en función de la dimensión de la calidad: aplicación de normas ISO 9000, normas ISO 14000 y procesos de control de calidad total.

Este método es usado para corregir las matrices de factores y poder observar finalmente cuáles variables son las que proporcionan mayor impacto frente al fenómeno del éxito empresarial. Al realizar la corrección de errores de estimación, 
Regresión análisis factorial variables dimensión de calidad

\begin{tabular}{|c|c|c|c|c|}
\hline \multicolumn{5}{|c|}{ Correlación de análisis factorial Número de observaciones $=19$} \\
\hline \multicolumn{5}{|c|}{ Método: factores principales Retención de factores $=3$} \\
\hline \multicolumn{2}{|c|}{ Rotación: (sin rotación) } & \multicolumn{3}{|c|}{ Número de parámetros $=10$} \\
\hline Factor & $\begin{array}{l}\text { Valores } \\
\text { propios }\end{array}$ & Diferencias & \multicolumn{2}{|c|}{ Proporción acumulado } \\
\hline Factor 1: control total de calidad & 1,28838 & 0,41944 & 0,6276 & 0,6276 \\
\hline Factor 2: ISO 9.000 & 0,86895 & 0,47146 & 0,4233 & 1,0509 \\
\hline Factor 3: ISO 14.000 & 0,39749 & 0,58204 & 0,1936 & 1,2445 \\
\hline Factor 4: calidad superior compet. & $-0,18455$ & 0,13291 & $-0,0899$ & 1,1546 \\
\hline Factor 5: tecnología de punta & $-0,31746$ & 0,00000 & $-0,1546$ & 1,000 \\
\hline
\end{tabular}

Fuente: elaboración de los autores.

Tabla 8.

Cargas de factores y varianzas únicas.

\begin{tabular}{|c|c|c|c|c|}
\hline Variables & Factor 1 & Factor 2 & Factor 3 & Singularidad \\
\hline Control total calidad & 0,3310 & 0,3112 & $-0,4601$ & 0,5819 \\
\hline Normas ISO 9000 & 0,7740 & 0,1916 & $-0,0558$ & 0,3611 \\
\hline Normas ISO 14000 & 0,6374 & 0,0013 & 0,3882 & 0,4430 \\
\hline Calidad superior productos & $-0,0372$ & 0,6590 & 0,1388 & 0,5451 \\
\hline Tecnología de punta & $-0,4148$ & 0,5488 & 0,1129 & 0,5141 \\
\hline
\end{tabular}

Fuente: elaboración de los autores.

en la tabla 10 se logró identificar que el factor 1 (certificación en normas ISO 14000), con un valor del 49,91\%, posee el mayor nivel de contribución para la dimensión de la calidad.

Como factor 2 surge la adquisición de tecnología de punta, con un $43,84 \%$, seguida del factor 3, procesos de control de la calidad, con un $44,52 \%$. Dados estos resultados, la predicción de factores permitió establecer con base en las correcciones entre la matriz variancia y covarianza, un valor más ajustado para el cálculo de cada una de las variables que representan la composición de la dimensión de calidad, lo que establece como resultado la ecuación [3]:
Dimensión de calidad E.F $=49,91 \%$ certificación en normas ISO $14.000+43,84 \%$ tecnología de punta $+44,52 \%$ control total de la calidad $+k$

\section{Análisis de la dimensión de innovación}

De igual forma que en el análisis anterior, para la dimensión de innovación se desarrollaron los mismos procedimientos, al realizar la matriz de varianza y covarianza (tabla 11), donde se encontró que ningún factor alcanzó un eigenvalues superior a 1,0, ni que el valor de $\mathrm{Chi}^{2}$ es mayor a 0,05. En este caso particular se demuestra que los datos expresan niveles de dependencia y que, por tanto, caen en zona de rechazo. 
Tabla 9.

Regresión del análisis factorial corregido en dimensión calidad

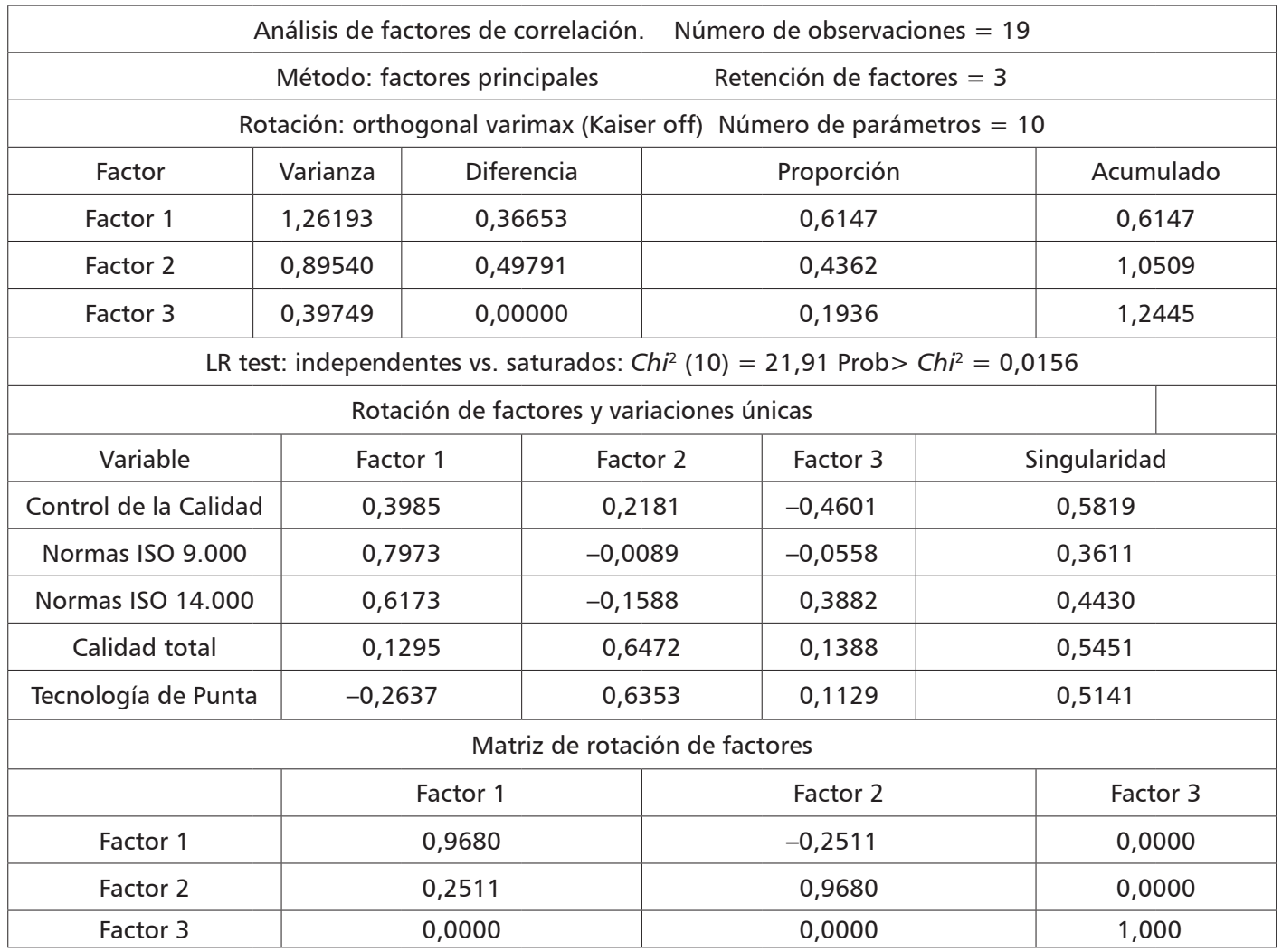

Fuente: elaboración de los autores.

Tabla 10.

Predicción exacta de factores calidad

\begin{tabular}{|c|c|c|c|}
\hline Variable & Factor 1 & Factor 2 & Factor 3 \\
\hline Control de la calidad & $-0,07121$ & 0,02252 & 0,44529 \\
\hline Normas ISO 9000 & 0,38470 & $-0,00962$ & 0,39010 \\
\hline Normas ISO 14000 & 0,49912 & 0,02903 & $-0,25478$ \\
\hline Calidad total & 0,07277 & 0,43033 & 0,05948 \\
\hline Tecnología de punta & $-0,06939$ & 0,43843 & $-0,05081$ \\
\hline
\end{tabular}

Fuente: elaboración de los autores.

Lo que se interpreta es que, mediante el análisis individual de los cinco factores, ninguno de ellos logra valores significativos, lo cual hace necesario realizar la reducción de estos para identificar variables que alcancen el nivel de confianza superior al 90\%. Efectuado este procedimiento, se visualiza en la tabla 12 que para la dimensión de innovación, los factores que contribuyen al éxito empresarial son en su orden: factor 1 , procesos de investigación y desarrollo $(I+D)$ con un valor del 50,67\%; factor 2, participación de clientes y empleados con un $31,51 \%$, y como factor 3 , el lanzamiento de nuevos productos con un $13,78 \%$. 
Tabla 11.

Regresión análisis factorial dimensión innovación

\begin{tabular}{|c|c|c|c|c|}
\hline $\begin{array}{c}\text { Correlación de análisis } \\
\text { factorial }\end{array}$ & & $\begin{array}{c}\text { Número de } \\
\text { observaciones }= \\
19\end{array}$ & & \\
\hline \multicolumn{2}{|c|}{ Método: factores principales } & & \multicolumn{2}{|c|}{ Retención de factores $=03$} \\
\hline \multicolumn{2}{|c|}{ Rotación: (sin rotación) } & & \multicolumn{2}{|c|}{ Número de parámetros $=10$} \\
\hline Factor & Valores Propios & Diferencia & Proporción & Acumulado \\
\hline Factor 1 & 0,52585 & 0,25898 & 1,2049 & 1,2049 \\
\hline Factor 2 & 0,26687 & 0,24366 & 0,6115 & 1,8164 \\
\hline Factor 3 & 0,02321 & 0,09122 & 0,0532 & 1,8696 \\
\hline Factor 4 & $-0,06802$ & 0,24347 & $-0,1559$ & 1,7137 \\
\hline Factor 5 & $-0,31149$ & -- & $-0,7137$ & 1,0000 \\
\hline \multicolumn{5}{|c|}{ LR test: independentes vs saturados: $C h i^{2}(10)=3,68$ Prob $>C h i^{2}=0,9605$} \\
\hline
\end{tabular}

Fuente: elaboración de los autores.

Tabla 12.

Reducción de factores dimensión innovación

\begin{tabular}{|c|c|c|c|c|}
\hline Variable & Factor 1 & Factor 2 & Factor 3 & Singularidades \\
\hline Investigación de mercados & 0,1087 & 0,2621 & $-0,0013$ & 0,9195 \\
\hline Benchmarketing & 0,3807 & 0,2807 & $-0,0194$ & 0,7759 \\
\hline Participación empleados/clientes & $-0,3005$ & 0,3151 & $-0,0386$ & 0,8089 \\
\hline Investigación y desarrollo & 0,5067 & $-0,1073$ & $-0,0485$ & 0,7294 \\
\hline Nuevos productos & 0,1487 & 0,0923 & 0,1378 & 0,9504 \\
\hline
\end{tabular}

Fuente: elaboración de los autores.

Paso siguiente, el modelo realiza el proceso de corrección de factores, encontrando que los resultados cambian, tal y como se aprecia en la tabla 13. En este análisis, se logró identificar que la variable Benchmarketing desplaza a la participación de empleados y clientes como el segundo factor de importancia en esta dimensión.

Tras efectuar la última etapa de ajuste de los factores analizados, para poder con ello establecer una predicción más exacta del comportamiento del fenómeno, se logró identificar frente a la variable de innovación, que los 3 factores que representan en mejor medida los datos finales (tabla 14) resultan ser como factor 1: investigación y desarrollo $(I+D)$ que cuenta con un valor del $36,40 \%$, factor 2: procesos de Benchmarketing con 36,34\% y el factor 3: lanzamiento de nuevos productos con $14,67 \%$.

Analizando detenidamente los resultados, se concluye que las variables que impulsan a la dimensión de innovación como factores de éxito empresarial son las expresadas en la ecuación [4]:

Dimensión de innovación $=36,41 \%$ investigación y desarrollo $+36,34 \%$ benchmarketing $+14,67 \%$ lanzamiento de nuevos productos $+k$

\section{Análisis de la dimensión de planeación estratégica}

Nuevamente se desarrollaron los mismos procesos de cálculo aplicados en los factores de calidad 
Tabla 13.

Regresión análisis factorial dimensión innovación corregido

\begin{tabular}{|c|c|c|c|c|}
\hline $\begin{array}{c}\text { Correlación de análisis } \\
\text { factorial }\end{array}$ & & & $\begin{array}{c}\text { Número de } \\
\text { observaciones }=19\end{array}$ & \\
\hline \multicolumn{2}{|c|}{ Método: factores principales } & & & Retención de factores $=3$ \\
\hline \multicolumn{4}{|c|}{ Rotación: ortogonal varimax } & Número de parámetros $=10$ \\
\hline Factor & Varianza & Diferencia & Proporción & Acumulado \\
\hline Factor 1 & 0,43274 & 0,07276 & 0,9916 & 0,9916 \\
\hline Factor 2 & 0,35998 & 0,33677 & 0,8249 & 1,8164 \\
\hline Factor 3 & 0,02321 & 0,00000 & 0,0532 & 1,8696 \\
\hline \multicolumn{5}{|c|}{ LR test: independente vs. saturado: $C h i^{2}(10)=3,68$ Prob $>C h i^{2}=0,9605$} \\
\hline \multicolumn{5}{|c|}{ Carga de factores y varianzas únicas } \\
\hline Variable & Factor 1 & Factor 2 & Factor 3 & Singularidades \\
\hline Investigación de mercados & $-0,0702$ & 0,2749 & -0.0013 & 0,9195 \\
\hline Benchmarketing & 0,1363 & 0,4529 & $-0,0194$ & 0,7759 \\
\hline $\begin{array}{c}\text { Participación empleados/ } \\
\text { clientes }\end{array}$ & $-0,4294$ & 0,0720 & $-0,0386$ & 0,8089 \\
\hline Investigación y desarrollo & 0,4699 & 0,2179 & $-0,0485$ & 0,7294 \\
\hline Nuevos productos & 0,0636 & 0,1630 & 0,1378 & 0,9504 \\
\hline \multicolumn{4}{|c|}{ Matriz de Rotación de Factores } & \\
\hline & Factor 1 & Factor 2 & Factor 3 & \\
\hline Factor 1 & 0,8003 & 0,5996 & 0,0000 & \\
\hline Factor 2 & $-0,5996$ & 0,8003 & 0,0000 & \\
\hline Factor 3 & 0,0000 & 0,0000 & 1,0000 & \\
\hline
\end{tabular}

Fuente: elaboración de los autores.

Tabla 14.

Predicción exacta de factores innovación

\begin{tabular}{|c|c|c|c|}
\hline Variable & Factor 1 & Factor 2 & Factor 3 \\
\hline Investigación & $-0,06764$ & 0,20744 & 0,01208 \\
\hline Benchmarking & 0,06511 & 0,36342 & 0,01037 \\
\hline Participación de empleados & $-0,32375$ & 0,09555 & $-0,04830$ \\
\hline I + D & 0,36401 & 0,14804 & -0.03326 \\
\hline Nuevos procesos & 0,02922 & 0,10506 & 0,14679 \\
\hline
\end{tabular}

Fuente: elaboración de los autores. 
e innovación, donde la dimensión de la planeación estratégica obtuvo los datos representados en la tabla 15: factor 1, alianzas estratégicas, con $69,28 \%$; factor 2, estrategia de internacionalización de productos, con $33,22 \%$, y factor 3, capitalización de utilidades, con $7,17 \%$, valor que resultó ser poco significativo para el análisis.

Al realizar el procedimiento de corrección de factores de la tabla 16 , destacan como variables que aporta al éxito dentro de la dimensión de planeación estratégica las mismas mencionadas en el resultado anterior, sin encontrar un valor representativo para un posible factor 3 , dado que $0,07 \%$ no representa ningún nivel de contribución en este sentido.
Para lograr valores definitivos, se realizó la predicción exacta de factores, con lo cual se obtuvo la tabla 17, donde el factor 1 es alianzas estratégicas con $40,48 \%$, mientras que el factor 2 es la internacionalización de los productos con un valor del $37,70 \%$.

El factor 3 no se involucra en este análisis, en razón a que no logra desarrollar valores significativos para la contribución de la dimensión de planeación estratégica en el éxito empresarial. Por lo tanto, se concluye a través de la ecuación [5]:

Dimensión de planeación estratégica $=40,48 \%$ alianzas estratégicas $+36,34 \%$ internacionalización de los productos $+k$

Tabla 15.

Regresión análisis factorial dimensión planeación estratégica

\begin{tabular}{|c|c|c|c|c|}
\hline Correlación de análisis factorial. & & $\begin{array}{l}\text { Número de } \\
\text { observaciones } \\
=19\end{array}$ & & \\
\hline Método: factores principales & & \multicolumn{2}{|c|}{ Retención de factores $=3$} & \\
\hline Rotation: (sin rotación) & & \multicolumn{3}{|c|}{ Número de parámetros $=10$} \\
\hline Factor & Valores propios & Diferencia & Proporción & Acumulado \\
\hline Factor 1 & 1,26766 & 0,94785 & 1,1123 & 1,1123 \\
\hline Factor 2 & 0,31981 & 0,30834 & 0,2806 & 1,3930 \\
\hline Factor 3 & 0,01147 & 0,20116 & 0,0101 & 1,4030 \\
\hline Factor 4 & $-0,18969$ & 0,07995 & $-0,1664$ & 1,2366 \\
\hline Factor 5 & $-0,26963$ & 0,00000 & $-0,2366$ & 1,0000 \\
\hline \multicolumn{5}{|c|}{ LR test: independents vs saturado: $C h i^{2}(10)=11,98$ Prob $>C h i^{2}=0,2865$} \\
\hline \multicolumn{5}{|c|}{ Cargas de factores y varianzas únicas } \\
\hline Variable & Factor 1 & Factor 2 & Factor 3 & Singularidades \\
\hline Modelo de planeación estratégica & $-0,3094$ & 0,2936 & 0,0608 & 0,8144 \\
\hline Indicadores de gestión & $-0,6602$ & 0,1062 & 0,0183 & 0,5525 \\
\hline Alianzas estratégicas & 0,6928 & $-0,0626$ & 0,0437 & 0,5142 \\
\hline Internacionalizar productos & 0,4900 & 0,3322 & 0,0197 & 0,6491 \\
\hline Capitalización utilidades & $-0,1264$ & $-0,3287$ & 0,0717 & 0,8708 \\
\hline
\end{tabular}

Fuente: elaboración de los autores. 
Tabla 16.

Regresión análisis factorial dimensión plan estratégica corregida

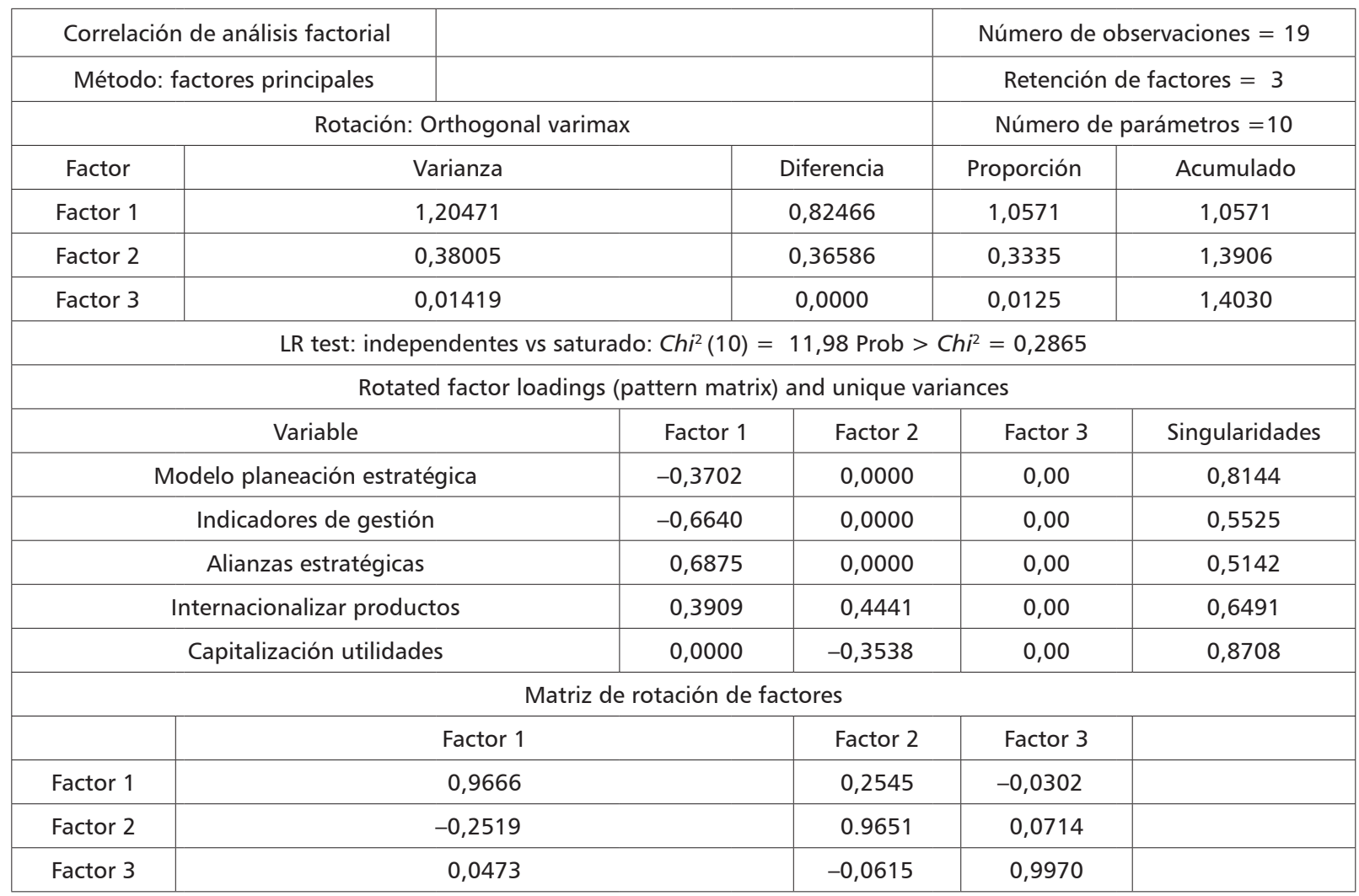

Fuente: elaboración de los autores.

Tabla 17.

Predicción exacta de factores planeación estratégica

\begin{tabular}{|c|r|r|r|}
\hline \multicolumn{4}{|c|}{ Coeficientes de puntuación, método de factores } \\
de regresión \\
\hline Variable & Factor 1 & Factor 2 & Factor 3 \\
\hline $\begin{array}{c}\text { Modelo de } \\
\text { planeación } \\
\text { estratégica }\end{array}$ & $-0,16562$ & 0,18916 & 0,08829 \\
\hline $\begin{array}{c}\text { Indicadores de } \\
\text { gestión }\end{array}$ & $-0,36199$ & 0,01833 & 0,05434 \\
\hline Alianzas estratégicas & 0,40480 & 0,01955 & 0,05307 \\
\hline $\begin{array}{c}\text { Internacionalizar } \\
\text { productos }\end{array}$ & 0,12500 & 0,37702 & 0,03670 \\
\hline $\begin{array}{c}\text { Capitalización } \\
\text { utilidades }\end{array}$ & 0,01190 & $-0,25973$ & 0,05856 \\
\hline
\end{tabular}

Fuente: elaboración de los autores.

En definitiva, los factores de calidad, innovación y planeación estratégica con base en los cálculos anteriores representan las dimensiones con mayor nivel de contribución para mejorar las condiciones actuales de una organización familiar y potencializar un mayor nivel de éxito empresarial. Los análisis econométricos de las demás dimensiones no lograron significancia estadística sustancial, situación que no significa que son de menor importancia para la gestiones, dado que lo expresado en el modelo simboliza que todas las dimensiones son vitales para el buen desempeño de una organización, pero que al hacer un mayor énfasis en las tres señaladas, existe una alta probabilidad de generar condiciones que incremente en gran medida la condición de éxito empresarial, definido en la ecuación [6].

EEF $=44 \%$ calidad (ISO $14.00049 .91 \%+$ tecnología de punta $43,84 \%$ + control total de la calidad 44,52\%) + 43\% innovación (I + D 36,41\% 
+ Benchmarketing 36,34\% + lanzar nuevos productos $14,67 \%)+46 \%$ planeación estratégica (creación alianzas estratégicas 40,48\% + internacionalización de los productos 37,70\%) + $k$

\section{CONCLUSIONES}

Teniendo como base la argumentación teórica acerca de los elementos generadores del éxito empresarial, así como los resultados obtenidos en el desarrollo de la investigación mediante el planteamiento del modelo econométrico propositivo formulado, se pueden expresar en forma puntual las siguientes conclusiones:

- El concepto del éxito empresarial en las empresas familiares es una temática que trasciende el ámbito corporativo y gubernamental, pues son las organizaciones que mayor contribución realizan en Colombia y el mundo a la generación de empleo, riqueza y calidad de vida. Resulta evidente que, en el caso colombiano, a pesar de su gran importancia para la economía nacional, existe una fuerte ausencia de estudios y proyectos investigativos que permitan su adecuada caracterización y proyección, razón por la cual se debe promover la creación de nuevas líneas de investigación en el ámbito académico y estatal, así como políticas que fomenten su fortalecimiento, crecimiento sostenible y competitividad tanto en el ámbito local como internacional.

- Indiscutiblemente, la condición de éxito en las organizaciones familiares se construye en primera medida sobre la base de crear un ambiente que logre distanciar en la medida correcta los entornos de familia, propiedad y empresa; situación que solo es posible a través de la profesionalización y el desarrollo de protocolos administrativos de primer nivel. En este sentido, la información obtenida en este estudio estableció que la condición de ser una empresa familiar (dimensión familiness) no representa un factor que contribuya a alcanzar la condición del éxito empresarial, aspecto que se demuestra en que las grandes empresas (consideradas exitosas) obtienen un buen desempeño a partir de separar el entorno familiar del empresarial a niveles óptimos, lo cual fomenta una toma de decisiones objetiva con altos estándares de profesionalización y la vinculación de nuevos inversionistas.

- Frente al análisis de la ecuación que define al modelo econométrico del éxito empresarial, resaltan las dimensiones de la calidad, innovación y planeación estratégica como los factores de mayor relevancia, aspectos que resultan lógicos, pues son vitales en el desarrollo de procesos productivos y de gestión en cualquier tipo de organización, al intentar competir con elementos diferenciadores en las actuales condiciones de globalización de los mercados.

- Al establecer el presente modelo econométrico de gestión que formula factores internos generadores del éxito en empresas familiares, se busca delinear un concepto de orden administrativo que contribuya a establecer planes de acción frente a los objetivos de sostenibilidad, rentabilidad, crecimiento e impacto social que demandan especialmente las micro, pequeñas y medianas organizaciones de este tipo en el ámbito colombiano como latinoamericano. Por tal razón, el modelo resultante no debe ser visto como un único esquema de gestión, sino como un elemento crítico para el debate empresarial y académico de sus resultados y conclusiones, con la firme intención de servir como herramienta guía en la toma de decisiones de las empresas familiares, en momentos en 
los que se deben afrontar grandes retos asociados con las condiciones del mercado y el cambio generacional que miles de ellas deben enfrentar en la presente década.

- Finalmente, bajo el enfoque estructural de la población de estudio que fueron las empresas familiares, es oportuno resaltar que, sumado a los resultados del modelo econométrico, es necesario implantar estrategias complementarias que soporten el buen desempeño organizacional, tales como son la adopción de órganos de gobierno, manejo de protocolos, profesionalización de empleados e implementación de planes de sucesión, en la medida que poco servirá impulsar acciones en los tres factores señalados en este análisis, sino se garantiza la eliminación de los permanentes conflictos entre familia, propiedad y empresa.

\section{REFERENCIAS.}

1. Antognolli, S. (2008). Empresas familiares: sus mejores amigos. Recuperado de http://www.derkra.com/ files/empresas-familiares.htm

2. Aronoff, C. y Ward, J. (1999). Juntas de trabajo exitosas en la empresa familiar. Ciudad de México: McGraw-Hill.

3. Arroyo, P. y Barber, C. (2004). Aspectos positivos y negativos que engloban a una empresa familiar. Recuperado de http://www.esmas.com/emprendedores/pymesint/empresasfiliales

4. Arrieta, D. (2009). Empresas familiares: cuando llegan los terceros. Recuperado de http://www.iae.edu. ar/antiguos/Documents/ Revista16/Revista16_68al71

5. Astrachan, J. y Shanker, M. (2003). Family businesses contribution to the U.S. economy: A closer look. Family Business Review, 16, 211-219.

6. Belausteguigoitia, I. (2003). Empresas familiares. Su dinámica, equilibrio y consolidación. Ciudad de México: McGraw-Hill.

7. Backes-Gellner, U. (2001). Personalökonomik: fortgeschrittene Anwendung für das Management. Stuttgart: Schaffer-Poeschel Publications.

8. Batista-Fogueta, J. Coendersb, G. y Alonso, J. (2004). Análisis factorial confirmatorio. Su utilidad en la validación de cuestionarios. Revista de Medicina, 11, 21-27.

9. Berbis, F. (2006). Yo soy competitivo, y tú... ¿Eres productivo? Recuperado de http://www.rankia.com/ blog/berbis-swap /niveles-de-competitividad

10. Boston Consulting Group (2011). Empresas familiares en América Latina. Recuperado de http://www.businessreviewamericalatina.com/leadership/134/Empresas-familiares-en-Am\%C3\%A9rica-Latina

11. Cámara de Comercio de Bogotá (CCB) (2006). Centro de documentación. Recuperado de http://www. latinpyme.com.co/asp_noticia.asp?ite_id

12. Casado, L. (1994). Psicología del desarrollo de la organización. Madrid: Centro de Estudios Ramón Areces.

13. Crosby, P. (1990). La organización permanentemente exitosa. Ciudad de México: McGraw-Hill.

14. Danies-Lacouture, R. (2006). Informe estadístico de sociedades de familia en Colombia. Bogotá: Superintendencia de Sociedades.

15. Davis, A. (2001). Definitions and Typologies of the Family Business. Harvard Business School, nota 802-007. 
16. Davis, J. y Tagiuri, R. (1996). Bivalent Attributes of the Family Firm. Family Business Review, 9(2), 199-208.

17. Davis, J. (2008). El desafío de profesionalizar una empresa familiar. Recuperado de http://goo.gl/4BuXUj

18. Donckels, R. y Fröhlich, E. (1991). ¿Are family businesses really different? European experiences from STRATOS. Family Business Review, 4, 149-160.

19. Drucker, P. (2002). Los desafíos de la gerencia para el siglo XXI. Bogotá: Norma.

20. Dyer, W. (1986). Cultural change in family firms. San Francisco: Jossey Bass.

21. Efamiliar. (2006). El protocolo familiar. Asociación Madrileña de la Empresa Familiar. Ejemplo de protocolo familiar. Recuperado de http://www.efamiliar.org/articulo/16/6/

22. Escorcia, A. y Duque, G. (2005). Comportamiento del sector textil y confecciones en Colombia. Bogotá: Universidad de los Andes.

23. Expansión. (2007). La sucesión en la empresa familiar. Recuperado de http://www.inexmoda.org.co/ textilConfecci\%C3\%B3n/ElsectorTextilydelaConfecci\%C3\%B3nColombiano/tabid/280/Default.aspx

24. Fernández, G. y Fernández, S. (2007). La gerencia en las empresas familiares. Journal of Management for Value, 2(1), 1-19.

25. Fracica, G., Camacho, L., Giraldo, F. y Gómez, I. (2008). La industria manufacturera colombiana en la economía mundial. Bogotá: Universidad de La Sabana.

26. Fundes Colombia (2008). Dinámica de la empresa familiar pyme. Bogotá: Fotolito.

27. Gaither, N. y Frazier, G. (1999). Administración de la producción y operaciones (8. ${ }^{\mathrm{a}}$ ed.). Ciudad de México: Thomson.

28. Gallo, M. y Amat, J. (2003). Los secretos de las empresas familiares centenarias. Barcelona: Deusto.

29. Gallo, M. (1995). Empresa Familiar. Barcelona: Praxis.

30. Gallo, M. (1998). La sucesión en la empresa familiar. Colección de Estudios e Informes, 12.

31. García-Tenorio, J. y Pérez, M. (1999). El éxito empresarial. Sus niveles de análisis y formas alternativas para su evaluación. Revista de Dirección, Organización y Administración de Empresas, (21), 188 -197.

32. Gersick, K., Davis J., Hampton, M. y Lansberg, I. (1997). Empresas familiares. Generación de empresas familiares. Ciudad de México: McGraw-Hill.

33. Giménez, G. (2005). La dotación de capital humano de América Latina y el Caribe. Revista de la CEPAL, $86,103-122$.

34. Gimeno, A. (2004). El desempeño en la empresa familiar: un estudio causal de los factores y variables internas (tesis doctoral). Barcelona: Universidad Ramón Llull.

35. Gómez-Betancourt, G. (2005). iSon iguales todas las empresas familiares? Bogotá: Norma.

36. Goodstein, L., Nolan, T y Pfeiffer, J. (1998). Planeación estratégica aplicada. Bogotá: McGraw-Hill.

37. Guerrero, C. (2008). Econometría aplicada. Ciudad de México: Trillas.

38. Johanson, J. y Wiedersheim, P. (1975). The internationalization process of the firms: Four Swedish Case Studies. Journal of Management Studies, 12(3), 305-322.

39. Johnson, P. (1985). The family in business. San Francisco: Jossey-Bass.

40. Kang, N. y Sakai. K. (2000). International strategic alliances, their role in industrial globalisation OECD Science, Technology and Industry Working Papers. 
41. Kotler, P. y Armstrong, G. (2003). Fundamentos de marketing (6.ㄹ ed.). Bogotá: Pearson.

42. Lansberg, I., Perrow, E. L. y Rogolsky, S. (1988). Family business as an emerging field. Family Business Review, 1, 1-8.

43. Llopis, J. (2000). Dirigiendo: 11 factores claves del éxito Empresarial (2. ${ }^{a}$ ed.). Barcelona: Gestión 2000.

44. López, M. (2004). Negocios familiares. Recuperado de http://www.esmas.com/emprendedores/pymesint/ empresas

45. Lozano, M. (2001). El protocolo en las empresas de propiedad familiar. Revista Estudios Gerenciales, 74, 49-67.

46. Malfavón, P. (2004). Aspectos positivos y negativos, que engloban a una empresa familiar. Recuperado de http://www.esmas.com/emprendedores/pymesint/empresasfiliale

47. Meza, C. (2007). Econometría fundamental. Bogotá: Universidad de La Salle.

48. Neubauer, F. y Lank, A. (1999). Family business: Its Governance and Sustainability. Deusto: Routledge Publishing.

49. Pérez, F. y Fernández, H. (2009). Econometría. Conceptos básicos. Medellín: Ecoe Ediciones.

50. Pfeffer, J. (1998). La ecuación humana. Cómo diseñar y dirigir empresas de alto rendimiento. Barcelona: Gestión 2000.

51. Porter, M. (1980). Competitive strategy: Techniques for analyzing industries and competitors. Nueva York: Free Press.

52. Porter, M. (1987). Ventaja competitiva, creación y sostenimiento de un desempeño superior. Ciudad de México: Cecsa.

53. Porter, M. (1996). What is strategy? Harvard Business Review, 74, 6-18.

54. Poza, E. (2004). Empresas familiares. Ciudad de México: Thomson.

55. Rendón, O. (2014). El sector textil en Colombia. El Mundo. Recuperado de http://www.elmundo.com/ portal/noticias/economia/el_sector_textil_crece_a_paso_lento_en_colombia.php\#.VuIQpfnhAbO

56. Revista Fortune (2010). Las 500 empresas más grandes del mundo. Recuperado de https://directoriodenoticias.wordpress.com/2011/07/09/las-500-empresas-mas-grandes-del-mundo-por-la-revista-fortune/

57. Serna, H. y Suárez, E. (2005). La empresa familiar, estrategias y herramientas para su sostenibilidad. Bogotá: Temis.

58. Superintendencia de Sociedades (SuperSociedades) (2006). Sociedades de familia en Colombia. Bogotá: Autor.

59. Superintendencia de Sociedades (SuperSociedades) (2008). Comportamiento del sector textil y confecciones 2005-2007. Bogotá: Autor.

60. Tamayo, M. (1994). El proceso de investigación científica (3. ${ }^{\text {a }}$ ed.). Bogotá: Limusa.

61. Torres, J. (2004). Estudio prospectivo de las empresas de confecciones organizadas en la ciudad de Bogotá. Bogotá: Universidad Externado de Colombia.

62. Trevinyo-Rodríguez, R. (2010). Empresas familiares. Visión latinoamericana. Ciudad de México: Pearson.

63. Van Dalen, D. y Meyer, W. (2004). Estrategia de la investigación descriptiva. Manual de técnica de la investigación educacional. Barcelona: Paidós. 
64. VanDer-Bruggen, M. (1998). El sector textil en Colombia. Bogotá: Becaria Generalitat de Catalunya.

65. Ward, J. (1988). The special role of strategic of planning for family Business. Family Business Review, 2(1), 105-117.

66. Ward, J. (2006). El éxito en los negocios de familia. Bogotá: Norma. 


\section{ANEXOS}

\section{Anexo 1. Parámetros de selección de empresas del estudio.}

- Empresas familiares que sean netamente colombianas.

- Empresas familiares colombianas que estén constituidas legalmente.

- Empresas familiares colombianas que pertenezcan al sector confecciones elaboración de prendas de vestir.

- Empresas familiares colombianas del sector confecciones prendas de vestir, clasificadas como grandes empresas (Ley 590 del 2000 / Ley 904 del 2004).

- Grandes empresas familiares colombianas del sector confecciones prendas de vestir que facturen ventas anuales superior a los $\$ 12.000$ millones de pesos (aprox. 5 millones de euros, 6 millones de dólares/año).

- Grandes empresas familiares colombianas del sector confecciones prendas de vestir con trayectoria comercial superior a quince años en el mercado nacional.

- Grandes empresas familiares colombianas del sector confecciones prendas de vestir que en la actualidad comercialicen productos en mercados internacionales.

Fuente: elaboración de los autores.

\section{Anexo 2. Ficha técnica de la entrevista a expertos/taller Delphi}

\begin{tabular}{|c|c|}
\hline Especialistas participantes & Nueve especialistas \\
\hline Métodos de obtención de Información & Entrevistas a especialistas bajo la metodología Delphi. \\
\hline Fecha de la toma de datos & Octubre, noviembre y diciembre de 2009. \\
\hline Número de preguntas & Veinte preguntas. \\
\hline Tipo de preguntas & $\begin{array}{c}\text { Diez preguntas cerradas, selección múltiple. } \\
\text { Diez preguntas abiertas de opinión. }\end{array}$ \\
\hline Análisis de datos & $\begin{array}{c}\text { Correlación de respuestas. } \\
\text { Interpretación de datos estadísticos. }\end{array}$ \\
\hline
\end{tabular}

Fuente: elaboración de los autores.

\section{Anexo 3. Ficha técnica de encuesta a directivos de empresas familiares exitosas}

\begin{tabular}{|c|c|}
\hline Población de estudio & $\begin{array}{l}\text { Grandes empresas familiares colombianas Internacionales del } \\
\text { sector confecciones. }\end{array}$ \\
\hline Tipo de investigación & Investigación descriptiva. \\
\hline Tamaño de la población & Censo empresarial - 72 compañías. SuperSociedades (2009). \\
\hline $\begin{array}{l}\text { Número de empresas participantes } \\
\text { en el estudio }\end{array}$ & $\begin{array}{l}\text { Respuesta efectiva para aplicación de la encuesta, } 19 \text { Grandes } \\
\text { empresas familiares colombianas del sector confecciones. }\end{array}$ \\
\hline Formato de preguntas & Preguntas cerradas con respuesta de selección múltiple. \\
\hline Total de preguntas de la encuesta & 35 preguntas. \\
\hline Periodo de trabajo de campo & 14 meses. \\
\hline Técnica de recolección de datos & Encuestas formales presenciales. \\
\hline Análisis de datos & $\begin{array}{l}\text { Correlación de respuestas. } \\
\text { Interpretación de datos estadísticos. }\end{array}$ \\
\hline
\end{tabular}

Fuente: elaboración de los autores. 